\title{
A Study Assessing Gender Distribution Using Maxillary Sinus
}

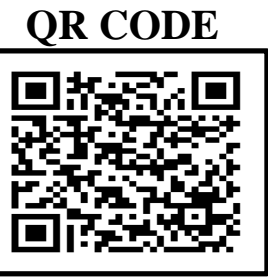

\section{SWATI PARHAR, AMANI MAHAJAN², ANKUR GOEL³ ${ }^{*}$ ANDLEEB MANHAS4}

INTRODUCTION: Corpse recognition is a difficult procedure. Comparison of both ante mortem and post-mortem records is essential and assists in identification of corpses. Typical methods of identification however sometimes may be inconclusive. Gender determination is an important aspect in identification of corpses. Previously skull, pelvis and the long bones have been used in gender determination. It has been reported earlier that maxillary sinus remains intact even when skull and long bones may be badly disfigured in incarnated victims.

AIM: The aim of this study was to examine whether the measurements of the maxillary sinuses may possibly be used for gender determination.

MATERIAL AND METHODS: Computed tomography scans of total of 50 Adults patients within the age range of 25 to 65 years from the previous dental records were taken. Sample comprised of $25(50 \%)$ males and $25(50 \%)$ females. The width, height and length was measured in all cases using CT images.

RESULTS: Maxillary sinus exhibits anatomic variability between genders. A significant difference in the length and height of maxillary sinus was observed with respect to males and females. $(\mathrm{p}<0.005)$

CONCLUSION: We conclude from the present study that the height and length of maxillary sinuses together with other bones can be used for gender determination when skeleton is not available.

KEYWORDS: Maxillary sinus, Computerized tomography, Forensic medicine, Gender determination

\section{INTRODUCTION}

Anthropometric characteristics are of primary significance to solve troubles associated with identification in forensic odontology. Craniometrical features can be used in identifying a person from remains of skull which may be found detached from its skeleton. Skeletal remains were used to identify gender of the person as the bones of the body are the last to die after death, next to the enamel of the teeth. ${ }^{1}$

In the field of forensic pathology, radiography finds its use in human identification, especially in cases where the body is either decomposed or burned (to any degree). The skull, pelvis, and femora are the most helpful remains for radiological gender determination. The maxillary sinuses have been documented in the literature to remain intact, although the skull and other bones may be severely disfigured in incinerated victims, and hence, they may also be used for identification of an individual. $^{2}$

The determination of gender is a major step of identification in forensic medicine with Computed
Tomography (CT) measurements of the maxillary sinuses being useful to support gender identification. In the absence of the while skeleton, the width, length, and height of maxillary sinus together can be used for gender determination of an individual.

Maxillary sinuses have been documented to remain intact, although the skull and other bones may be badly disfigured in incinerated victims and, thus, maxillary sinuses may be used for identification. Maxillary sinuses are two air-filled spaces that are present in the maxillary bone and can be of different sizes and types with slender walls. In the zygomatic process, the apex of the sinuses may stretch and may occupy the zygomatic bone. ${ }^{3,4}$

At the close of the second embryonic month, the maxillary sinuses starts developing. When deciduous teeth fall off, maxillary sinus stretch to the roof of the permanent teeth. Around 20 years of age, when the permanent teeth fully grow in oral cavity, the maxillary sinuses attain their full sizes. Variations in their shapes 


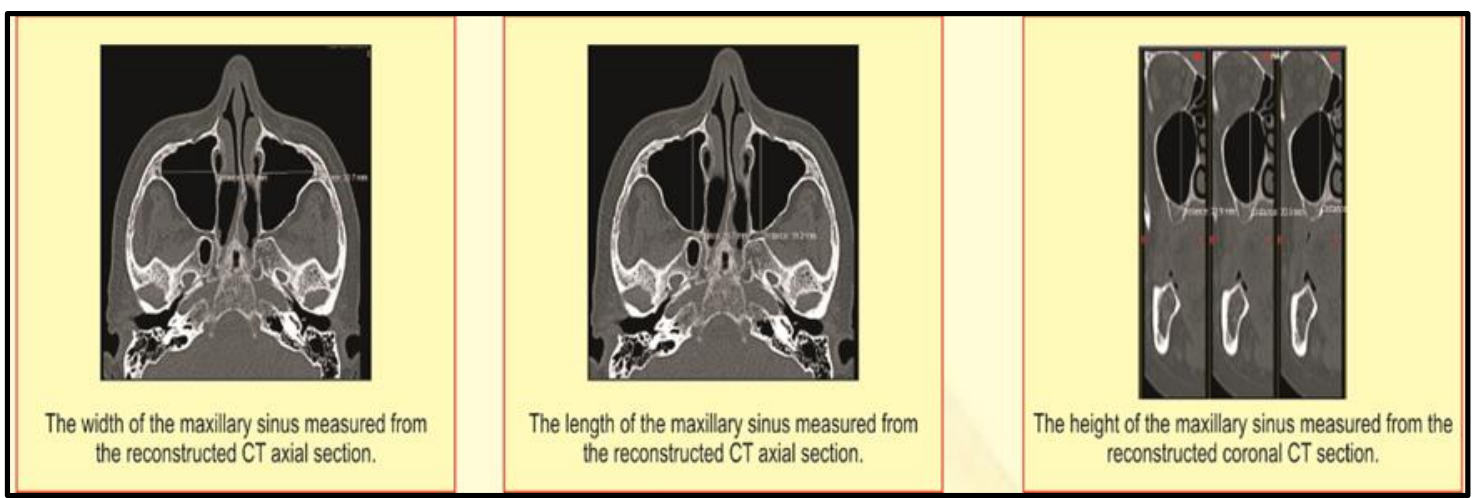

Figure 1. Height, width and length of maxillary sinus using a CT Scan.

and sizes occur during adulthood, particularly due to the tooth loss. Genetic disorders, post-infection and environmental factors are also known to affect the size of maxillary sinuses..$^{5-7}$

Radiology can help to provide specific measurements which may help in gender determination. Best imaging technique to determine the sino-nasal cavities is computer tomography (CT) scans with a good accuracy rate. In computerised tomography (CT) scans, measurements of the maxillary sinuses may be used to assess age and sex when other approaches are inconclusive, although these measurements are not error-free.

Hence, in the present study we aimed to examine whether or not various dimensional parameters of maxillary sinuses like width, length and height can be used for the purpose of gender determination.

\section{MATERIALS AND METHODS}

The present research was conducted in the department of oral and maxillofacial pathology. We included 100 cone beam CT scans of maxillary sinuses of patients who came for implants supported restorations and without any pathological findings. Patients selected were in the age range of $25-65$ years. Among total 100 cases, 50 were male and 50 were females.

When CT was performed, the patients did not have sedation or contrast medium. All the sections were coronal in planes. Measurements of height, width and length were made in coronal planes where the maxillary sinus was in its widest place as a measuring technique with the assistance of measurement equipment on the CT scan (figure 1 ).

Statistical analysis: Statistical analyses were completed using the SPSS version 20. Mean and standard deviations were recorded and percentages were also taken where required. Student t-test for was used to compare values between two comparable groups. p value $<0.05$ was considered as statistically significant.

\section{RESULTS}

In the present study we observed that maxillary sinus exhibited anatomic variability between both the genders. Mean value with standard deviations in relation to length, width and height are tabulated in the table 1. A significant difference in the length and height of maxillary sinus on both sides was observed with respect to males and females $(\mathrm{p}<0.05)$.

\begin{tabular}{|c|c|c|c|}
\hline \multicolumn{1}{|c|}{$\begin{array}{c}\text { MALE } \\
\text { PARAMETER }\end{array}$} & $\begin{array}{c}\text { FEMALE } \\
(\mathbf{n}=25)\end{array}$ & $\begin{array}{c}\text { p } \\
\text { VALUE }\end{array}$ \\
\hline $\begin{array}{c}\text { Width right } \\
\text { maxillary sinus }\end{array}$ & $22.79 \pm 4.9$ & $22.17 \pm 3.5$ & 0.698 \\
\hline $\begin{array}{c}\text { Height right } \\
\text { maxillary sinus }\end{array}$ & $34.82 \pm 5.7$ & $30.76 \pm 4.4$ & $0.038^{*}$ \\
\hline $\begin{array}{c}\text { Length of } \\
\text { maxillary sinus }\end{array}$ & $34.35 \pm 3.2$ & $30.72 \pm 4.7$ & $0.046^{*}$ \\
\hline $\begin{array}{c}\text { Width left } \\
\text { maxillary sinus }\end{array}$ & $23.49 \pm 5.3$ & $22.21 \pm 4.2$ & 0.472 \\
\hline $\begin{array}{c}\text { Height left } \\
\text { maxillary sinus }\end{array}$ & $34.35 \pm 7.1$ & $30.36 \pm 4.1$ & $0.043^{*}$ \\
\hline $\begin{array}{r}\text { Length of } \\
\text { maxillary sinus }\end{array}$ & $34.41 \pm 3.3$ & $30.98 \pm 4.6$ & $0.034^{*}$ \\
\hline
\end{tabular}

Table 1. Mean values in relation to length, width and height as recorded in study population 
In the present study, accuracy rates as observed showed that from right side $66.7 \%$ males and females were correctly identified, from left side $66.7 \%$ females and $60 \%$ males were identified correctly. Overall, the accuracy rate of the both right and left maxillary sinus together was $66.7 \%$ in females and $53.3 \%$ in males (figure 2).

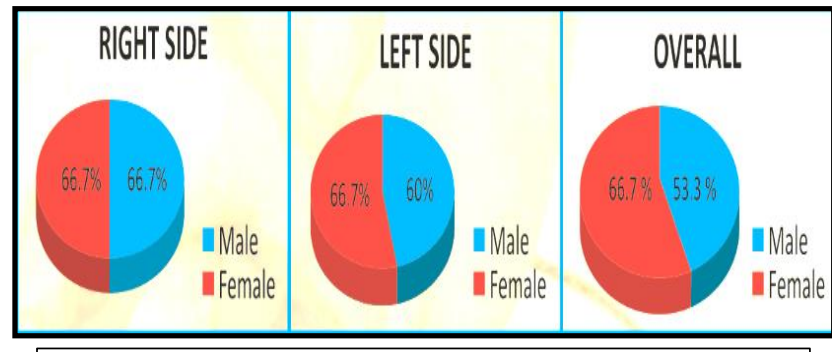

Figure 2. Accuracy rates observed in the present study

\section{DISCUSSION}

One of the major criteria of forensic identification is sex determination. The primary step to identification in medico-legal analysis is gender determination in both injured and mutilated dead bodies or from skeletal remains. Matching unique characteristics detected on dead bodies with data documented during an individual's life is a significant feature of forensics, and is accomplished using various techniques among which anthropological methods facilitate age and gender determination.

Results from the present study reveal that when height, length and width were compared between both the sexes, we observed that both height and length of right side were significantly greater among males in comparison to females. Even though the width of the sinus was greater in males in comparison to females, the difference was not significant.

Fernandes CL et al. ${ }^{8}$ from their study revealed that the volume of the maxillary sinuses was greater in the Males rather than females, and with a precision of 79 percent. Maxillary sinuses of males, were found to be larger, but narrower in men than in women in Europe. Kim HJ et al. ${ }^{9}$ reported that the maxillary sinuses are significantly larger in males as in comparison to females. Szılvassy J et al. ${ }^{10}$ from their results showed that left maxillary sinus was greater in dimensions in comparison to right sinus in both males and females.

Teke HY et al. ${ }^{3}$ aimed to enquire whether or not the various dimensions of the maxillary sinuses can be used to determine gender in their study population. Their analysis revealed that the ability of the maxillary sinus size to identify gender-was around $69.4 \%$ in relation to females and it was around $69.2 \%$ in relation to males. Hence they concluded that dimensional evaluation of maxillary sinuses on $\mathrm{CT}$ can be helpful for gender determination in forensic medicine; however, with a relatively low-accuracy rate (less than $70 \%$ ).

In yet another study by Farias GA et al."1, overall, different dimensions of maxillary sinuses were considerably greater in males. No statistically significant difference was observed between both the sides i.e the right and left side, within each study group. The most dimorphic measurement was the height, with a precision of $77.7 \%$ regarding gender estimation. They posted a gender estimate of $87.8 \%$ among women and $80 \%$ among males, with an accuracy level of $84 \%$. They concluded that the formula developed using $\mathrm{CBCT}$ scans via calculations in the maxillary sinus showed an accuracy of 84 percent for sex estimation and can be applied in the Brazilian population as a complementary tool for human identification.

In 2013, 30 dry skulls of southern Indian origin were examined by Vidya CS et al. ${ }^{12}$ The maxillary sinus height, weight, width and volume on each side were determined. The findings revealed that the measurements and the maxillary sinus volume of males were significantly greater relative to females. Statistically important values were shown by left width and right-sided volume.

\section{CONCLUSION}

We conclude from the present study that both height and length of maxillary sinuses along with observations of other bones can be used during the process of gender determination in forensic studies especially when the complete skeletal remains are not available.

\section{REFERENCES}

1. Nagare SP, Chaudhari RS, Birangane RS, Parkarwar PC. Sex determination in forensic identification, a review. J Forensic Dent Sci. 2018;10(2):61-6. https://doi.org/10.4103/jfo.jfds_55_17

2. Cameriere R, Ferrante L, Mirtella D, Rollo UF, Cingolani M. Frontal sinuses for identification: quality of classifications, possible error and potential corrections. J Forensic Sci. 2005;50(4):1-4.

3. Teke HY, Duran S, Canturk N, Canturk G. Determination of gender by measuring the size of the 
maxillary sinuses in computerized tomography scans. Surg Radiol Anat. 2007;29:9-13

4. Plenk JR, Tschabitscher M. (1986) Entwicklung, makro und mikromorphologie der kieferho"hle. In: Watzek G, Matejka M (eds) Erkrankungen der Kieferho“ hle. Springer-Verlag, Wien, New York, pp 112

5. Jovanic S, Jelicic N, Kargovska-Klısarova A. Le de'veloppement post-natal et les rapports du sinus maxillaire. Acta Anat. 1984;118:122-8.

6. Kaptanoglu K, Ozdemir B. (2001) Gender dimorphism from skull tickness: a preliminary study (in Turkish). In: Annual forensic medicine meeting proceeding, _ Istanbul, pp 153-156 11.

7. Karakas S, Kavaklı A. Morphometric examination of the paranasal sinuses and mastoid air cells using computed tomography. Ann Saudi Med. 2005;25(1):415 .

8. Fernandes CL. Forensic ethnic identification of crania: The role of the maxillary sinus - A new approach. Am J Forensic Med Pathol. 2004;25:302-13.
9. Kim HJ, Yoon HR, Kim KD, Kang MK, Kwak HH, Park HD, Han SH, Park CS. Personal computer based three dimensional reconstruction and simulation of maxillary sinus. Surg Radiol Anat. 2002;24:393-9.

10. Szılvassy J. The importance of the rontgenologic methods fort he prehistoric and recent history excavation areas. In: Up-to-date problems of the fominit evolutionVero"ff. U" berse-Mus Bremen 1989;9:79-128.

11. Farias GA, de Gamba OT, Yamasaki MC, Groppo FC, Haiter Neto F, Possobon RF. Development and validation of a formula based on maxillary sinus measurements as a tool for sex estimation: a cone beam computed tomography study. Int J Legal Med. 2019;133(4):1241-9. https://doi.org/10.1007/soo414-0181869-6.

12. Vidya CS, Shamasundar NM, Manjunatha B, Raichurkar K. Evaluation of size and volume of maxillary sinus to determine gender by ${ }_{3} \mathrm{D}$ computerized tomography scan method using dry skulls of South Indian origin. Int J Curr Res Rev. 2013;5:97-100.

Cite this article as:

Parhar S, Mahajan A, Goel A, Manhas A. A Study Assessing Gender Distribution

Using Maxillary Sinus. Int Healthc Res J. 2020;4(6):162-165.

https://doi.org/10.26440/IHRJ/0406.09284

AUTHOR AFFILIATIONS: (*Corresponding Author)

1. Reader, Department of Oral Pathology, Swami Devi Dyal Hospital and Dental College, Barwala, Panchkula, India

2. Senior Lecturer, Department of Oral Pathology, Swami Devi Dyal Hospital and Dental College, Barwala, Panchkula, India

3. MDS (Oral Pathology), Consultant Dental Surgeon, Panchkula

4. MDS (Oral Pathology), Consultant Dental Surgeon, Jammu 